\title{
The Balance between Interleukin 5 and Interleukin 10 Level in Persistent Atopic Asthma after House Dust Mite Allergen Dermatophaigoides pteronyssinus (Der p) Stimulation
}

\author{
Rahmaya Nova Handayani ${ }^{1,2}$, Faisal Yunus ${ }^{3}$, Ermita Isfandiary Ibrahim ${ }^{4}$, and \\ Iris Rengganis ${ }^{5}$ \\ 1Doctoral Program in Biomedical Science, Faculty of Medicine, Universitas Indonesia, Jakarta, \\ Indonesia \\ ${ }^{2}$ Bachelor of Nursing Study Program of Harapan Bangsa University, Indonesia \\ ${ }^{3}$ Department of Pulmonology and Respiratory Medicine, Medicine Faculty of Indonesia \\ University, Persahabatan Hospital, Jakarta, Indonesia \\ ${ }^{4}$ Department of Medical Physiology, Medicine Faculty of Indonesia University, Jakarta, Indonesia \\ ${ }^{5}$ Department of Internal Medicine, Faculty of Medicine, Indonesia University, Dr.Cipto \\ Mangunkusumo Hospital, Jakarta, Indonesia
}

Corresponding Author: Rahmaya Nova Handayan mayanova2005@gmail.com

Received: 1 February 2020 Accepted: 8 February 2020 Published: 16 February 2020

Publishing services provided by Knowledge E

(c) Rahmaya Nova Handayani et al. This article is distributed under the terms of the Creative Commons Attribution License, which permits unrestricted use and redistribution provided that the original author and source are credited.

Selection and Peer-review under the responsibility of the IC-BIOLIS Conference Committee.

\section{Abstract}

Asthma is a chronic inflammation of the respiratory tract characterized by coughing, shortness of breath, wheezing and limited expiratory aiffow. Interleukin 10 (IL-10) is a cytokine produced by $T$ regulators which functions to suppress pro-inflammatory production and development. Interleukin 5 (IL-5) is glycoprotein produced by Th2 which acts as a proinflammatory agent. This study aimed to analyze how to balance between IL-10 and IL-5 levels on persistent atopic asthma. The study design was an experimental research method with invitro study used isolation and cell culture of Peripheral Blood Mononuclear Cell (PBMC) with negative control Roswell Park Memorial Institute (RPMI) medium, positive control Phytohaemaglutinin (PHA) and house dust mite allergen stimulation $10 \mu \mathrm{l}$. This study involved 39 samples asthmatic. There was a significant increase in IL-5 levels after stimulation of house dust mite allergens with p: 0.000 ; there was a significant decrease in IL-10 levels after house dust mite allergen stimulation with p: 0.000 . Our study suggests that IL-5 and IL-10 balance is related to persistent atopic asthma after house dust mite allergen Der $\mathrm{p}$ stimulation.

Keywords: Interleukin 5, Interleukin 10, Atopic Asthma, house dust mite allergen, ELISA

\section{Introduction}

Asthma is a chronic inflammatory airway disease with wheezing, dyspnea, chest tightness, coughing with airflow during expiration. Classification of asthma based on the severity of intermittent asthma, mild persistent, moderate persistent and severe persistent.[1, 2] Many inflammatory cells involved especially cells mast, eosinophils, T 
lymphocyte cells, macrophages, neutrophils, and epithelial cells. Environmental factors and various other factors are related to the causes or triggers of airway inflammation in asthmatic patients. Inflammation can be found in various forms of asthma such as allergic asthma, non-allergic asthma, occupational asthma and asthma triggered by aspirin.[3] Cytokines are polypeptides produced by the body in response to stimuli of microbes and other antigens and act as mediators in immune and inflammatory reactions.[4] Among the cytokines produced by Th2, IL-4 and IL-5 have the most important roles. Interleukin 5 is also found in the eosinophils and tissue mast cells that are activated in patients with allergic dermatitis, allergic rhinitis, and asthma. This increases the suspicion that IL-5 is present in atopic patients, especially the late-type response.[5]

Interleukin-10 is a cytokine which has a role in reducing the inflammatory process regulated by Th2 and also has a beneficial effect in improving airway structure. In addition, IL-10 can reduce type I collagen synthesis and vascular smooth muscle proliferation. The effect of IL-10 on airway response is still contradictive. One study shows that IL-10 decreases airway response, but other studies have found that IL-10 increases allergen-induced airway responses even though there is a decrease in eosinophil uptake.[6, 7] Management of asthma is focused on preventing attacks and preventing asthma complications. One of the efforts made is the culture of a healthy lifestyle through sports such as asthma exercise. Based on previous studies that asthma exercise can reduce the frequency of asthma attacks characterized by improvements in lung function, but there has been no research related to Th2 biomarkers, IL-5 which functions as proinflammatory and IL-10 as an anti-inflammatory in stimulating house dust mite allergens. The purpose of this study was to analyze Interleukin 5 (IL-5) is glycoprotein produced by Th2 which acts as a proinflammatory agent. This study aimed to analyze how to balance between IL-10 and IL-5 levels in persistent atopic asthma stimulated by house dust mite allergens.

\section{Methods}

The design of this study was an experimental study pre-post-test group design. The number of research subjects was 39 people. IL-5 and IL-10 were taken from the supernatant by isolating peripheral blood mononuclear cell (PBMC) with 3 interventions, namely the Roswell Park Memorial Institution (RPMI) medium as a negative control, phytohemagglutinin (PHA), and home dust mite allergen stimulation Dermatophagoides 
pteronyssinus (Der p) $10 \mu \mathrm{l}$ and incubated for 72 hours. Analysis of IL-5 and IL-10 levels using enzyme-linked immunosorbent assay (ELISA).

This study was conducted at the Hospital Prof. Dr. Margono Soekarjo, Purwokerto, Indonesia and the laboratory were conducted in the integrated laboratory of the Medicine Faculty oflndonesia University for ELISA reading, while isolation of PBMC was carried out in the research laboratory of Medical Faculty of Jenderal Soedirman University. This study results had been tested by the Board of Medicine the Faculty of Universitas Indonesia with the ethical clearance number was 998 / UN. F1 / ETIK / 2017.[8] Statistical analysis used was the Wilcoxon test because the data was not normally distributed.

\section{Results}

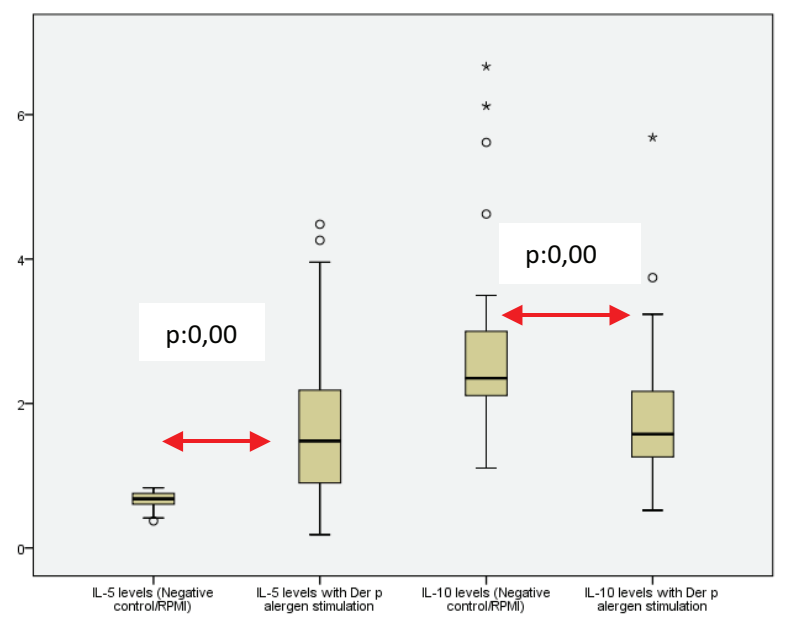

Figure 1: Interleukin-5 Levels, Interleukin-10 levels of Negative Control and Derp house dust mite allergen stimulation.

\section{Discussion}

Table 1 shows the characteristics of the research subjects. It can be seen that the number of female respondents is higher than the number of male respondents. There were 30 asthmatic female respondents (76.9\%). The number of respondents with the age of 18 to 65 years were 38 respondents (97.4\%). According to the study of Zillmer and Postma et al, asthma mostly experienced byadult women.Some studies on genetics state that the incidence of asthma is associated with $X$ chromosomes and hormones especially in atopic asthma. This is related to the hormone progesterone, the increasing mucus secretion, and prostaglandin synthesis during the premenstrual phase and abnormal 
TABLE 1: Characteristics of respondents[8].

\begin{tabular}{|c|c|c|}
\hline Variables & n (\%) & $95 \% \mathrm{Cl}$ \\
\hline \multicolumn{3}{|l|}{ Gender } \\
\hline Man & $9(23.1)$ & 21.24--24.96 \\
\hline Woman & 30 (76.9) & 73.5--75.7 \\
\hline \multicolumn{3}{|l|}{ Address } \\
\hline South Purwokerto & $1(2.6)$ & $1.8--3.4$ \\
\hline West Purwokerto & 7 (17.9) & 16.15--19.65 \\
\hline North Purwokerto & $8(20.5)$ & $18.7--22.3$ \\
\hline East Purwokerto & $23(59)$ & 55.3--62.72 \\
\hline \multicolumn{3}{|l|}{ Occupation } \\
\hline Housewife & $18(46.2)$ & 44.4--48.04 \\
\hline Teacher & $10(25.6)$ & 23.71--27.49 \\
\hline Entrepreneur & $6(15.4)$ & 13.73--17.07 \\
\hline Student & $2(5.1)$ & 40.23--61.77 \\
\hline Private & $3(7.7)$ & 64.13--89.87 \\
\hline \multicolumn{3}{|l|}{ Level of education } \\
\hline Elementary school & $10(25.6)$ & 23.71--27.49 \\
\hline $\begin{array}{l}\text { Junior high school/senior high } \\
\text { school }\end{array}$ & $11(28.2)$ & 26.28--30.17 \\
\hline Diploma/bachelor/postgraduate & $18(46.2)$ & $27.82--48.04$ \\
\hline \multicolumn{3}{|l|}{ Age (years) } \\
\hline Young age (18-65) & $38(97.4)$ & 97.27--97.52 \\
\hline Middle age (66-79) & $1(2.6)$ & 18.11--33.89 \\
\hline \multicolumn{3}{|l|}{ BMI } \\
\hline Normal & 37 (94.9) & 94.65--95.15 \\
\hline Light fat & $2(5.1)$ & 40.23--61.77 \\
\hline \multicolumn{3}{|l|}{ Fitness level } \\
\hline Good & $36(92.3)$ & 91.93--92.3 \\
\hline Medium & $3(7.7)$ & 64.13--89.87 \\
\hline \multicolumn{3}{|l|}{ Classification of asthma } \\
\hline Medium persistent & $14(35.9)$ & 33.85--37.95 \\
\hline Light persistent & $25(64.1)$ & 62.66--65.54 \\
\hline
\end{tabular}

regulation of $\beta 2$ Adrenergic receptors during the premenstrual phase and menstruation which exacerbates bronchial hyperactivity. Although the influence of endogenous 
estrogen in the airways is not clear yet, exogenous estrogen/synthetic can also affect the incidence of asthma in women.[9, 10]

Lange et al 2001 reported that the hormone estrogen can increase corticosteroid production which binds to globulin while the hormones estrogen and progesterone can affect the free level of cortisol causingthe decrease in the amount of cortisol which can lead to narrowing of the bronchi which eventually leads to bronchial asthma attacks. Estrogen hormones increase the adhesion of endothelial cells in blood vessels.Meanwhile, the combination of estrogen and progesterone hormones can increase eosinophil granulation which facilitates the occurrence of bronchial asthma attacks. It means that hormonal factors play an important role in the occurrence of asthma in women.[11, 12]

In terms of the occupation of the respondents, the majority of them were housewives (46.2\% or 18 people). One of the triggers of asthma is the entry of an allergen into one's airway which stimulates the occurrence of type 1 hypersensitive reactions. These allergens have two types which are indoor and outdoor ones. The outdoor allergens include house dust mites, pet allergens, cockroach allergens, and fungi. Indoor allergens come from homes that have carpets, heaters, coolers, room dividers, air humidity that can make the habitat of mites, cockroaches, fungi, bacteria, and insects from inside the house. One of the indoor allergens such as house dust mites is a common aeroallergen which triggers asthmatic patients. House dust mites will release protein-coated feces in each particle causing an allergic reaction for asthmatic patients when inhaling into the airways.[13]

Table 1 shows the highest level of education of the respondents is atthe level of higher education that are 18 people (42.6\%). Based on the study conducted by Atmoko 2009 that most of the education levels of asthma on research subjects are medium and high education levels. The level of education can be related to the ability of research subjects to control asthma. In this study, there wererespondents (58\%) who were to control their asthma.This ability can be influenced by their level of awareness and knowledge. The higher the level of education, the higher the level of awareness and knowledge in preventing something. This study is not in accordance with the study of Eagan et al 2004 and Bacon's 2009 which conveys the results that low education levels are at risk of developing asthma.[14]

Table 1 shows that BMI is a normal category with 37 research subjects $(94.9 \%)$ and there is one research subject (5.1\%) who experienced mild fat. The researchers excluded obesity-disturbing variables based on several hypotheses in other studies that explained there was a relationship between obesity and asthma. Being overweight 
or obese in a person can reduce lung compliance caused by excess fat tissue so that it can suppress the thoracic wall, infiltrate fat to the chest wall and increase blood volume to the lungs. Decreased lung volume is associated with a decrease in capillary diameter in the airways, which can alter the function of bronchial smooth muscle through the myosin actin cross-bridge cycle which can potentially increase obstruction and bronchial hyperactivity. Excessive obesity can also trigger systemic inflammation. Improved adipose tissue function can increase some serum concentrations in cytokines, receptors, and chemokines such as leptin, adiponectin, interleukin-4, interleukin 6 and C-reactive protein (CRP) which can contribute to the occurrence of asthma. Oxidative stress is associated with obesity which can cause inflammation of the airways.[15, 16]

Table 1 shows that the fitness level of the study subjects was mostly good as many as 36 research subjects (92.3\%). Based on the literature, increasing airway resistance in asthmatic patients is associated with decreased lung function. The thickening of the airway wall causes a decrease in the amount of oxygen in the blood so that it can reduce fitness level in cardiorespiratory function that is proven by the decrease in VO2max which is the main parameter of cardiorespiratory fitness level of asthma or chronic obstructive pulmonary disease (COPD), although there are some studies that report no difference cardiorespiratory fitness level, heart rate in asthma patients and healthy subjects. A good level of fitness can affect the physical exercise program given, 16 so that in this study the level of fitness became one of the criteria in the selection of research subjects because it was associated with the given asthma exercise training program.[17]

The biggest frequency of research subjects according to GINA 2017 asthma degree in this study was mild persistence of 25 research subjects (64.1\%). Asthma with more severity results in an inflammatory process in the airways and remodeling will occur (changes in structure and thickening of the airway wall) due to increased submucosal tissue, adventitia / the outermost layer of blood vessel walls consisting of connective tissue, smooth muscle, and connective tissue components. The ability to control asthma in the subject of this study, most of which were able to control 23 subjects (54\%). Asthma with more severe obstruction requires more intensive treatment, higher drug doses, and tighter supervision. This is closely related to the level of patient compliance to achieve better-controlled asthma. The researcher did not limit the study subjects who experienced Exercise-Induced Bronchoconstriction (EIB) because the study subjects were still encouraged to take inhalers a few hours before asthma exercise, this is wrong one way to prevent EIB. No research subjects in the study experienced EIB, although no screening of EIB subjects was conducted, but at the beginning, it was stated that 
asthma exercise was not forced and was in accordance with the ability of the research subjects with every 6 minutes of movement interspersed for about 1 minute.[18]

Based on Figure 1, it was found that IL-5 levels in the negative control were lower than IL-5 levels when Der $p$ allergen stimulation ( $p: 0,000)$ and IL-10 levels were higher in negative controls than IL-10 levels. Which was stimulated by Der $p$ house dust mites (p: 0,000) and there was a significant increase between IL-5 levels on Der $p$ house dust mites allergen stimulation with IL-10 levels after asthma exercise on allergen stimulation house dust mites Der p (p: 0,000). This is consistent with Fattouh's 2005 study that higher IL-5 levels were stimulated by house dust mite allergens. This is also in accordance with the Tamotii study, 2015 that there is a balance between IL-5 and IL-10 levels in the asthma group, namely an increase in IL-5 levels with stimulation of house dust mites Der $p$ in the asthma group and a decrease in IL-10 levels in the group asthma. According to Akdis et al 2004 research, regulator T cells can suppress Th2 responses. The balance between regulatory T cells and Th2 can cause allergies.

Based on Figure 1, the levels of IL-10 stimulated by Der p's house dust mite allergens were lower, and IL- 5 stimulated by Der $p$ house dust mites allergens were higher than negative controls. This shows the balance between Treg and Th2 namely IL-5 which is the result of Th2 and IL-10 produced by Treg. The high level of IL-5 is due to the sensitized/induced research subject which is the first contact to appear when the body produces IgE antibodies that are specific to allergies. The given Der $\mathrm{p}$ house dust mites stimulation, the body response to repeated exposure to these allergens. IL-10 levels after Der $\mathrm{p}$ house dust mite allergen stimulation significantly decreased compared to IL-10 levels in negative controls before asthma exercise, this was due to allergen stimulation causing IL-10 inadequacy in suppressing IL-5 due to stimulation of these allergens.

Some things can affect allergic diseases, namely environment and genetic risk factors that can change Th1 and Th2 production. Home dust mite allergens are the most suitable allergen test for stimulating lymphocytes. This research uses pure house dust mite allergens because it is in accordance with the previous theory pure allergens can lead to better sensitization processes. Decreased production of IL-5 in mononuclear cells with asthma patients may be due to two reasons, Th2 suppression response and increase in regulator inhibitors or cytokines such as IL-10 responses. According to Akdis et al 2004, Treg can specifically suppress Th2 responses. A disruption of the balance between Treg and Th2 can determine the direction of allergic development. In accordance with this study, was carried out isolation of PBMCs with negative controls (using RPMI medium) showed IL-5 levels were lower than IL-5 levels stimulated by house dust mite allergens, while IL-10 levels were negative controls using medium RPMI has a higher IL-10 level than 
IL-10 in stimulating house dust mite allergens. This is in accordance with Pavulraj's 2013 study that someone who has a genetic history will cause a predisposition to allergens in the body. When a person is exposed to allergens for the first time, there will be $\operatorname{lgE}$ formation that binds to mast cells, the process does not cause a direct allergic reaction but becomes sensitive to these allergens. If the individual is exposed again to the same allergen, a bond between IgE and mast cells will occur and cross-linking will occur. Mast cells along with cross-linking IgE will release histamine and other mediators resulting in an allergic reaction.[18,19]

\section{Conclusion}

House dust mite allergen stimulation can increase IL-5 and decreases IL-10

\section{Acknowledgement}

This research was funded by Ministry of Research and Technology of the Republic of Indonesia 2019

\section{Conflicts of Interest}

There are no conflicts of interest.

\section{References}

[1] Global Initiative for Asthma (GINA). Global strategy for asthma management and prevention. Bethesda (MD): Global Initiative for Asthma (GINA). 2016. Accessed from: www.ginasthma.com. March $5^{\text {th }} 2017$.

[2] Departertemen Penyehatan Lingkungan. Pedoman Pengendalian Asma. Jakarta:Departemen Kesehatan Kesehatan RI. Direktorat Jenderal Pengendalian Penyakit dan RI. 2013.

[3] Barnes PJ. Pathophysiology Of Asthma Br. J Clin Pharmacol.1996;42:3-10.

[4] Barnes PJ.The cytokine network in asthma and chronic obstructive pulmonary disease. National Heart \& Lung Institute. The Journal of Clinical Investigation. http://www.jci.org.2008;118:11

[5] Varricchi G\&Giorgio W. Canonica.The role of interleukin 5 and eosinophil in asthma. Expert Review of Clinical Immunology .2016;12 
[6] Hsia TC et al. The Contribution Of Interleukin-10Promoter Genotypes ToSusceptibility To Asthma In Adults. J. In Vivo: 2015;29:695-700.

[7] Zurry and Xystrakis E, Hawrylowicz C. Interleukin-10-Secreting Regulatory T Cells In Allergy And Asthma. Current Allergy And Asthma Reports. 2006;6(5):363 -- 371.

[8] Handayani RN, Yunus F, Rengganis I, llyas Ell, Nurwidya F. The effect of asthma exercise on cortisol hormone and interleukin-5 in the Indonesian patients with persistent asthma. J Nat Sc Biol Med. 2019;10(2):193-6.

[9] Postma DS. Gender Differences in asthma development and progression. Gend Med. 2007;4 Suppl B:S133-46.

[10] Zilmer LR, Gazzoti MR, Nascimento, Montealegre F, Fish J, Jardin JR. Gender Difference In The Perception Of Asthma And Respiratory Symptoms In a Population Sample Of Asthma Patients In Four Brazilian Cities. J Bras Pneumol. 2014;40(6):591598.

[11] Lange J, Parner J, Prescott E, Ulrik C, and Vestbo J. Exogenous female sex steroid hormone and risk of asthma and asthma-like symptoms: a cross-sectional study of the general population. Thorax. 2001 Aug;56(8):613-6.

[12] Tovey ER, Willenborg CM, Crisafulli DA, Rimmer J, Marks GB. Most personal exposure to house dust mite aeroallergen occurs during the day. Plos One. 2013 Jul;8(7):1-5.

[13] Brooks C, Peare N and Douwes J. The hygiene hypothesis in allergy and asthma: an update. Curr Opin Allergy Clin Immunol. 2013 Feb;13(1):70-7.

[14] Atmoko W. Hubungan usia dengan tingkat kontrol di Poliklinik Asma Rumah Sakit Persahabatan. FKUI; 2009.

[15] Beuther DA. Recent insight into obesity and asthma. Curr Opin Pulm Med. 2010 Jan;16(1):64-70.

[16] Fida N, Enquobahrie DA, Gelaye B, Qiu C, and Williams MA. Association of asthma with body mass index and adult weight change among reproductive-age women. $J$ Asthma. 2011 Sep;48(7):701-6.

[17] Mohammad I, Valiollah S and Vahid I. Maximal oxygen consumption in asthma patient before and after the aerobic training program. BFIJ. 2014;6(2):455-9. 